\title{
Frontières
}

\section{Il est venu au monde...}

\section{Jacques Salomé}

Volume 18, numéro 2, printemps 2006

La mort dans tous ses états

URI : https://id.erudit.org/iderudit/1073227ar

DOI : https://doi.org/10.7202/1073227ar

Aller au sommaire du numéro

Éditeur(s)

Université du Québec à Montréal

ISSN

1180-3479 (imprimé)

1916-0976 (numérique)

Découvrir la revue

Citer ce document

Salomé, J. (2006). Il est venu au monde... Frontières, 18(2), 76-76. https://doi.org/10.7202/1073227ar

Ce document est protégé par la loi sur le droit d'auteur. L'utilisation des services d'Érudit (y compris la reproduction) est assujettie à sa politique d'utilisation que vous pouvez consulter en ligne.

https://apropos.erudit.org/fr/usagers/politique-dutilisation/
Cet article est diffusé et préservé par Érudit.

Érudit est un consortium interuniversitaire sans but lucratif composé de l’Université de Montréal, l'Université Laval et l'Université du Québec à Montréal. Il a pour mission la promotion et la valorisation de la recherche. https://www.erudit.org/fr/ 


\section{IL EST VENU AU MONDE...}

$\overline{\text { Jacques Salomé, }}$

écrivain.

«Il est venu au monde

et je l'ai perdu avant même d'avoir pu le rencontrer»

m'a dit cette femme.

Et je n'ai pas su à l'époque,

lui dire ce que je sais aujourd'hui.

Que certains bébés,

se «donnent la liberté» d'apparaître,

de seulement apparaître dans la vie,

pour donner l'envie à l'un ou à l'autre

de leur géniteur... de naître aussi,

d'accéder à une co-naissance nouvelle.

Que certains enfants sont de passage,

pour montrer à l'un ou l'autre

de leur parent, un chemin,

pour témoigner d'un nouveau

choix de vie à faire.

Que certains bébés par leur disparition prématurée, leur mort subite,

apparemment injuste, invitent leur père ou leur mère, à oser un changement, que ceux-ci

n'avaient osé envisager de faire jusqu'alors.

Que certains enfants ont ce pouvoir de dire par leur présence fugitive de quelques mois à l'intérieur d'un ventre,

de quelques heures ou de quelques semaines

à l'aurore d'une existence,

une vérité unique: «je ne suis qu'une parcelle de vie».

Et de nous crier

avec leur disparition brutale

«ose ta vie car toi seul(e) la vivras».

Si nous savons entendre ce message, venu du plus profond de nos entrailles, du plus loin de notre histoire,

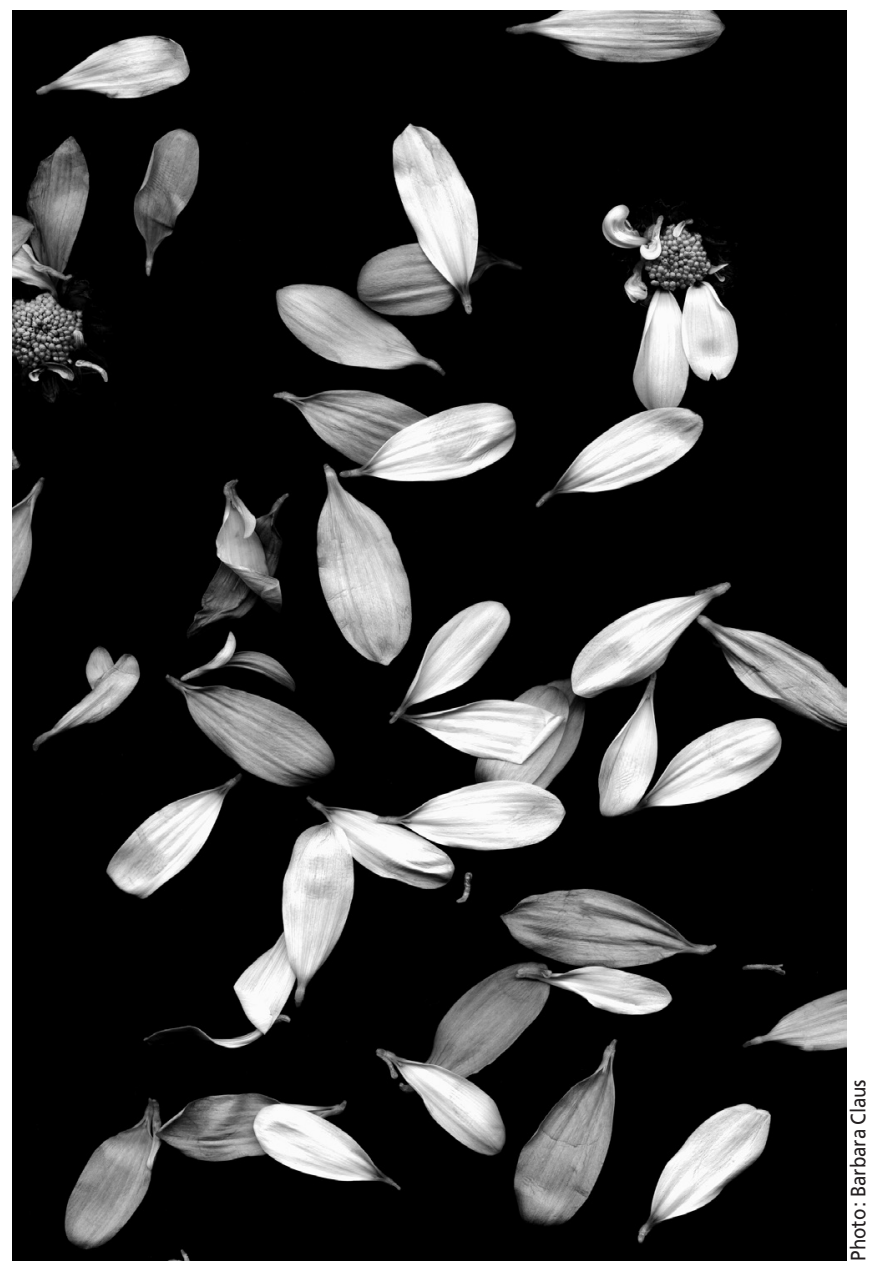

si nous acceptons de le recevoir... alors

la non-arrivée d'un petit fotus,

le départ brutal d'un bébé,

la disparition soudaine d'un enfant, prend un autre sens que celui d'une souffrance injuste ou d'une douleur irréparable.

Ce poème est tiré de Lettres à l'intime de soi, 2001, Paris, Albin Michel.

Jacques Salomé est aussi l'auteur de nombreux ouvrages, dont Papa, Maman écoutez moi vraiment, Albin Michel;

Car nul ne sait à l'avance la durée de vie d'un amour, Dervy; Je croyais qu'il suffisait de t'aimer, Albin Michel;

Une vie à se dire, Pocket. 